
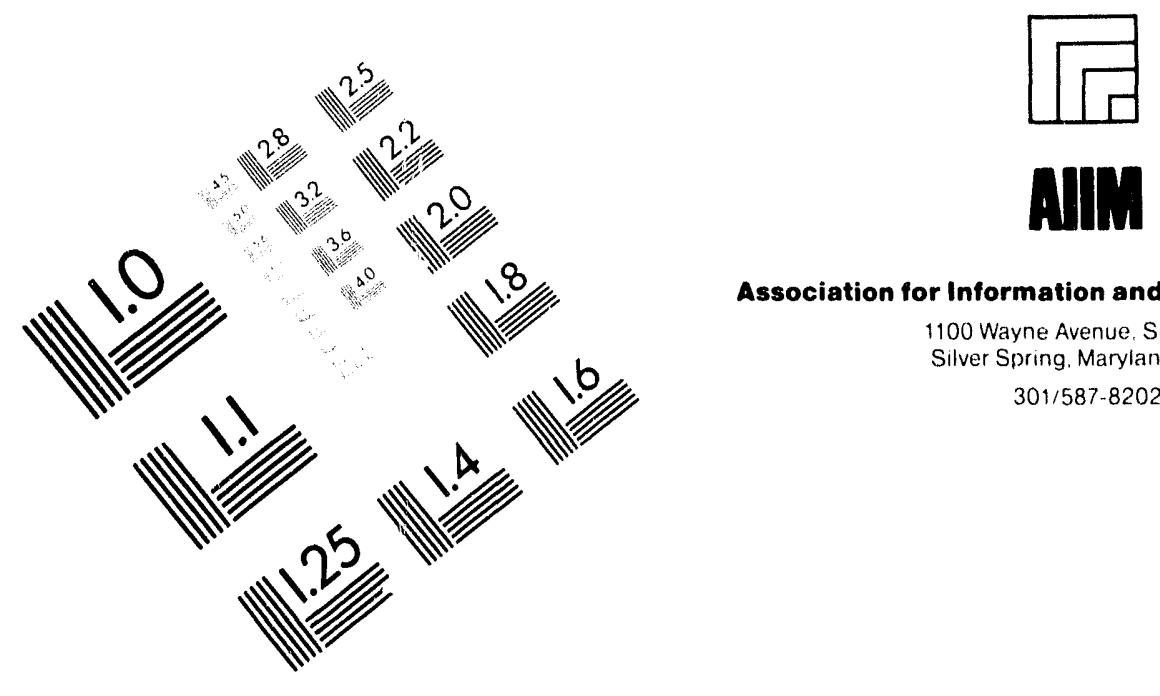

Association for Information and Image Management

1100 Wayne Avenue Suite 1100

Silver Soring. Maryiand 20910

$$
\text { 301/587-8202 }
$$

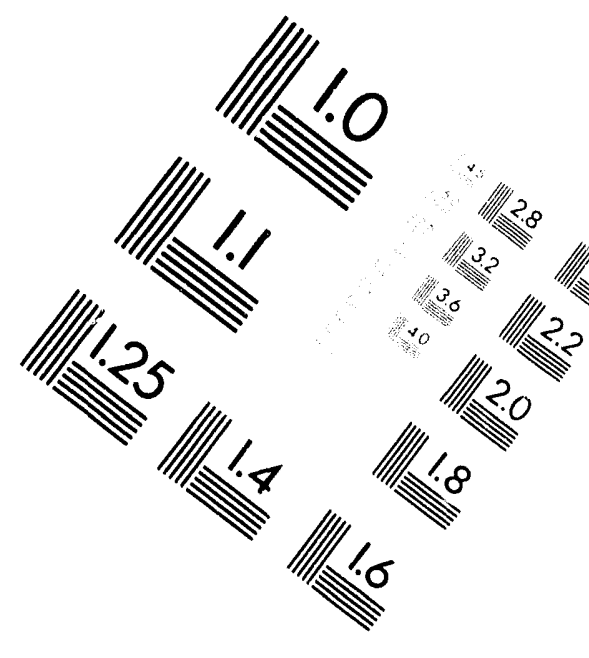

\title{
Centimeter
}

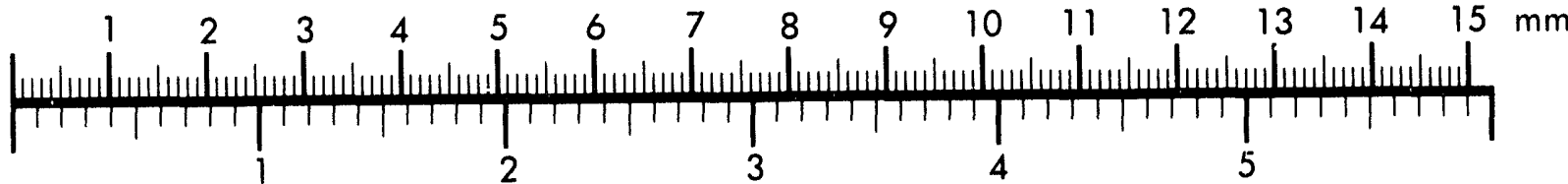
Inches
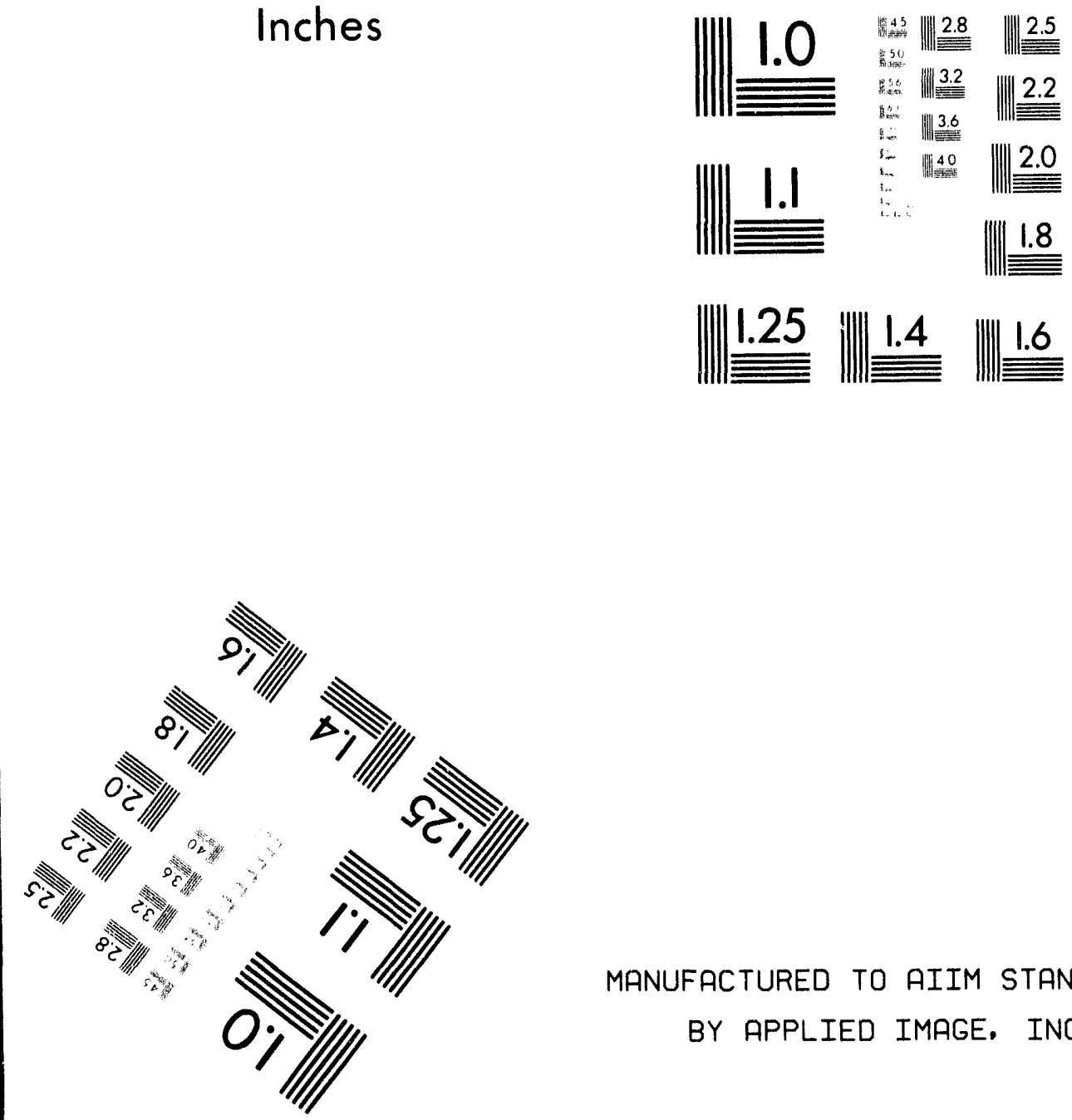

MANUFACTURED TO AIIM STANDARDS

$$
\text { BY APPLIED IMAGE, INC. }
$$

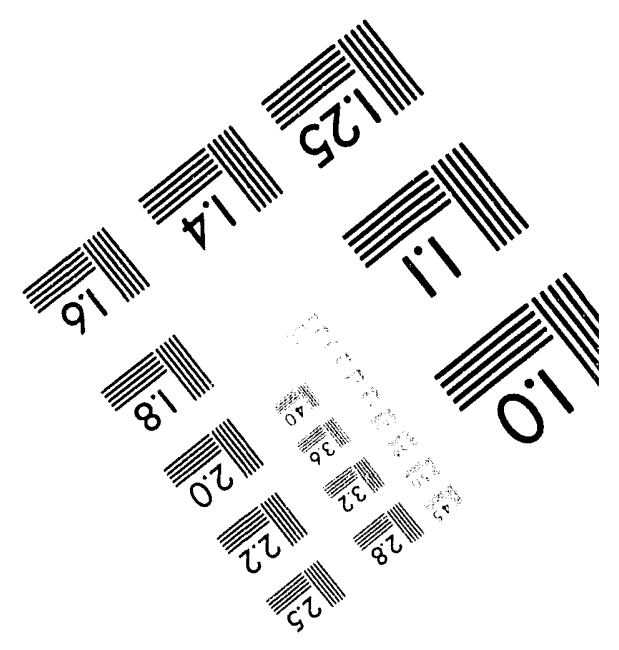



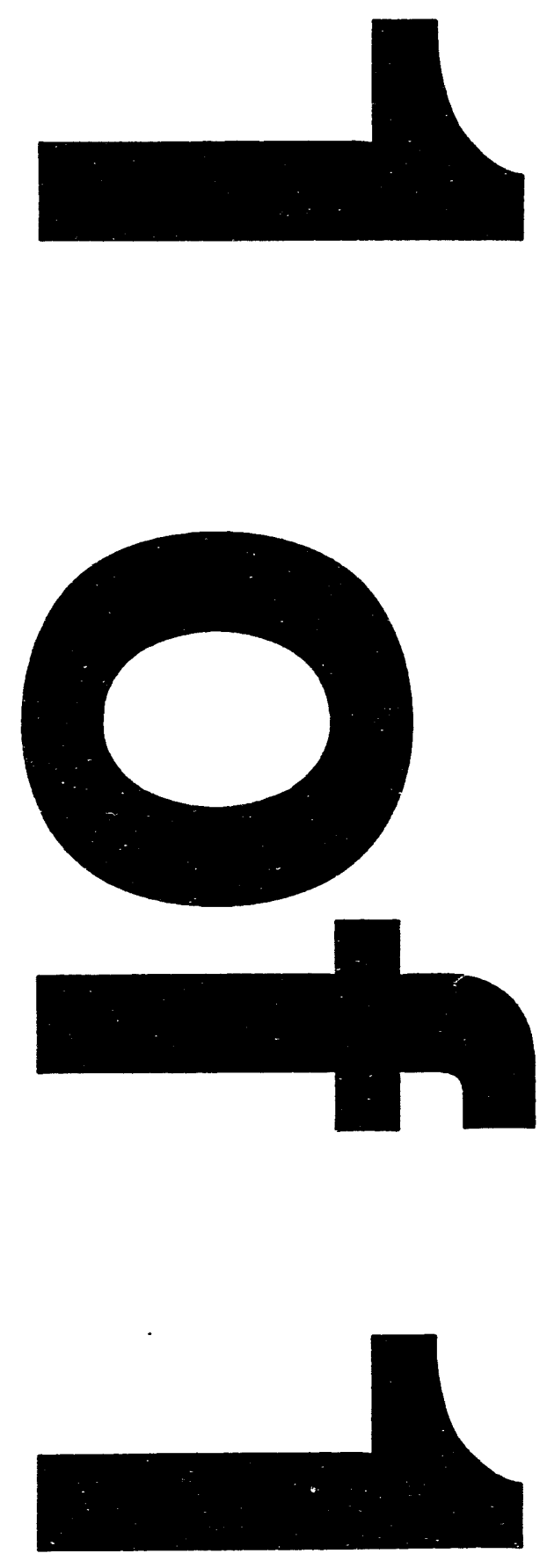
UCRL-JC-115362

PREPRINT

\section{Using Geophysical Techniques \\ To Control In Sítu Thermal Remediation}

Robin L. Newmark, S. Boyd, W. Daily, R. Goldman, R. Hunter,

D. Kayes, K. Kenneally,

A. Ramirez, K. Udell, M. Wilt

This paper was prepared for submittal to the

Symposium on the Application of

Geophysics to Engineering and Environmental Problems

Boston, MA

March 27-31, 1994

January 22, 1994

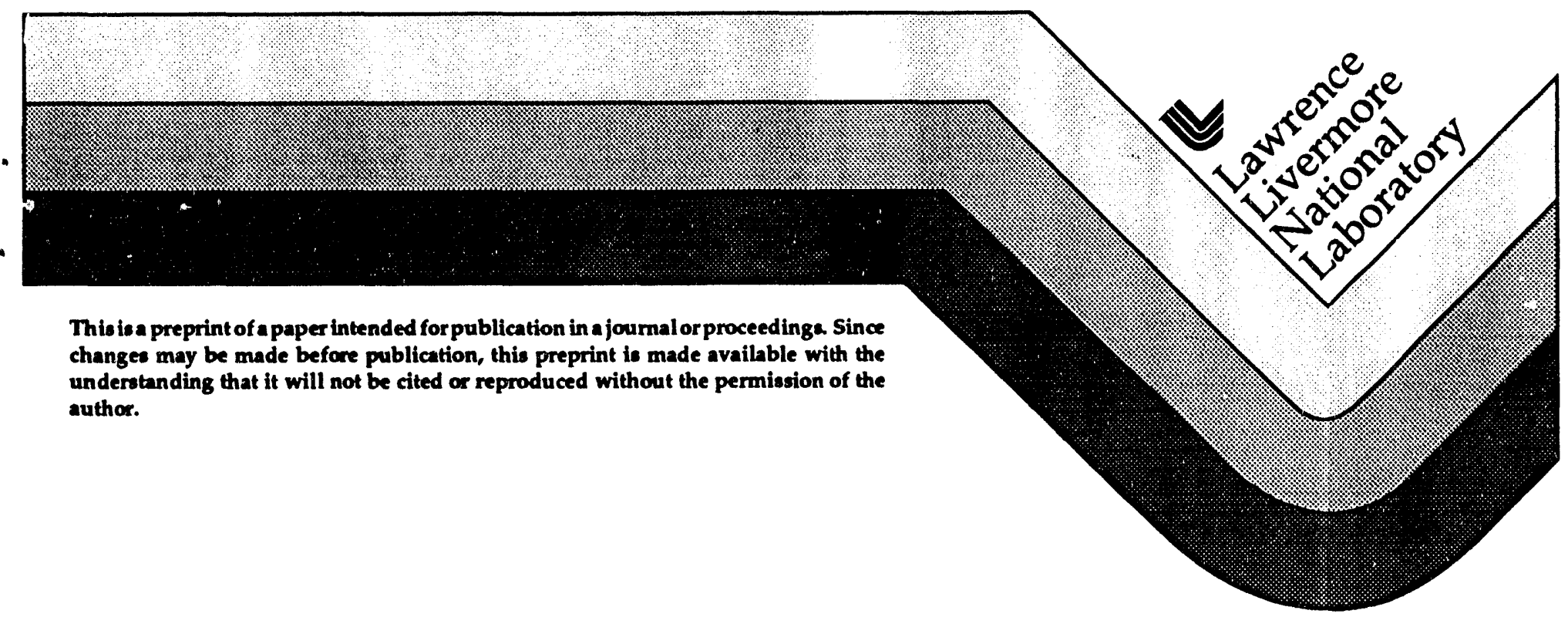




\section{DISCLAIMER}

This dacument was prepared as an account of work sponsored by an agency of the United States Government. Neither the United States Government nor the Uni versity of California nor any of their employees, makes any warranty, express or implied, or assumes any legal liability or responsibility for the accuracy, completeness, or usefulness of any information, apparatus, product, or process disclosed, or represents that its use would not infringe privately owned rights. Reference herein to any specific commercial products, process, or service by trade name, trademark, manufacturer, or otherwise, dass not necessarily constitute or imply its endorsement, recommendation, or favoring by the United States Government or the University of California. The views and opinions of authors expressed herein do not necessarily state or reflect those of the United States Government or the University of Califomia, and shall not be used for advertising or product endorsement purposes. 


\title{
Using Geophysical Techniques \\ To Control In Situ Thermal Remediation
}

\section{Robin L. Newmark and the Dynamic Underground Stripping Project Gasoline Spill Site Monitoring Team*}

Earth Sciences Division, L-208

Lawrence Livermore National Laboratory

PO Box 808

Livermore, California, 94551-9900

(510)-423-3644

\begin{abstract}
Monitoring the thermal and hydrologic processes that occur during thermal environmental remediation programs in near real-time provides essential information for controlling the process. Geophysical techniques played a crucial role in process control as well as for characterization during the recent Dynamic Underground Stripping Project demonstration in which several thousand gallons of gasoline were removed from heterogeneous soils both above and below the water table. Dynamic Underground Stripping combines steam injection and electrical heating for thermal enhancement with ground water pumping and vacuum extraction for contaminant removal. These processes produce rapid changes in the subsurface properties, including changes in temperature, fluid saturation, pressure and chemistry. Subsurface imaging methods are used to map the heated zones and control the thermal process. Temperature measurements made in wells throughout the field reveal details of the complex heating phenomena. During electrical heating, the clay-rich, electrically conductive units heat up, and fluids begin to circulate within the neighboring saturated permeable units. Unsaturated soils begin to dry out as temperatures increase. During steam injection, temperatures rise in the steamed zones, and saturation decreases. Since electrical properties are sensitive to changes in temperature, saturation and fluid electrical conductivity, electrical techniques are particularly useful for monitoring these changes. Electrical resistance tomography (ERT) provides near real-time detailed images of the heated zones between boreholes both during electrical heating and steam injection. Borehole induction logs show close correlation with lithostratigraphy and, by identifying the more permeable gravel zones, can be used to predict steam movement. They are also useful in understanding the physical changes in the field and in interpreting the ERT images. Tiltmeters provide additional information regarding the shape of the steamed zones in plan view. They were used to track the growth of the steam front from individual injectors. The rapid
\end{abstract}


response of the monitoring methods provided near-real time information regarding the thermal processes, thereby allowing the operations engineers to effectively control their subsurface progress.

${ }^{*}$ Contributors: S. Boyd1, W. Daily1, R. Goldman², R. Hunter ${ }^{3}$, D. Kayes ${ }^{2}$, K. Kenneally ${ }^{2}$, A. Ramirez ${ }^{1}, \mathrm{~K}$. Udell ${ }^{2}$, M. Wilt ${ }^{1}$,

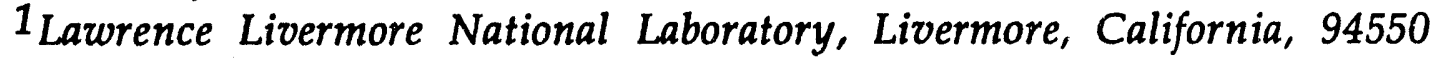

2 University of California, Berkeley, California, 94720

3 Infraseismic, Inc., Bakersfield, California, 93309

\section{INTRODUCTION}

Researchers at Lawrence Livermore National Laboratory have collaborated with specialists in the College of Engineering at the University of California at Berkeley (UCB) to develop a technique called Dynamic Underground Stripping ${ }^{1}$ to remove localized underground spills in a relatively short time. Dynamic Underground Stripping adds thermal energy to speed the removal of contaminants, utilizing complementary techniques to heat the heterogeneous soils: 1) steam flood strips organic contaminants from permeable zones, and 2) electrical resistance heating drives contaminants from less permeable zones into the more permeable zones from which they can be extracted. A third technology component is the use of geophysical monitoring to track and image the progress of the thermal fronts, providing feedback for control of the active processes (Figure 1).

A successful full-scale demonstration of Dynamic Underground Stripping on a gasoline-contaminated site has been completed. Approximately 90,000 cubic meters of soil were thermally treated at the LLNL gasoline spill site, consisting of unconsolidated alluvial interbeds of clays, sands and gravels.

Between 1952 and 1979, an estimated 17,000 gallons of gasoline may have been lost from one of four underground fuel tanks located at the former LLNL filling station (Dresen et al., 1986). After the subsurface plume developed, fluctuations in the water table over time trapped separate phase gasoline below the water table and smeared it through the low-permeability clay-rich soils. It has been estimated that it would take on the order of 200 years to satisfactorily clean up the site using conventional pump and treat methods (Udell and Hunt, 1987).

Six injection wells were installed encircling the region where separate phase gasoline was detected (about $40 \mathrm{~m}$ in diameter), with three central extraction wells capable of both pumping ground water and vacuum

1 Patent pending. 
extraction. Each injection well consists of two steam injectors, targeting each of the two zones identified as relatively permeable (at approximately 25 and 35 meters depth), and an electrical heating electrode, located in intervening clayrich interval.

An electrical pre-heat of the clay-rich soils was conducted during November and December, 1992 , resulting in an average $20^{\circ} \mathrm{C}$ temperature rise, with individual units reaching over $70^{\circ} \mathrm{C}$. This was performed to ensure that the electrical contrast between the resistive gravel zones and the conductive clay-rich zones would be maintained after the gravels were elevated to steam temperatures. During electrical heating, as the the clay-rich, electrically conductive units heated up, fluids began to circulate in the neighboring saturated permeable units. Unsaturated soils began to dry out as temperatures increased.

Most of the soil heating was accomplished with steam injection. Two series of steam passes were conducted, in February and in June, 1993. During the 10 weeks of recovery operations, over 7400 gallons of gasoline were removed from the central plume area. Our characterization indicated that this region contained about 6200 gallons of gasoline, half of which was above, and half below the water table, with separate phase contamination extending to $>40$ meters depth ( 8 meters below the static water table).

Subsurface imaging methods were used to map the heated zones and control the thermal processes; the ability to control these processes in nearreal time allowed us to heat most of the contaminated zone to $100^{\circ} \mathrm{C}$, with the coolest areas reaching $80^{\circ} \mathrm{C}$. In a previous demonstration of these technologies at a clean site, a number of technologies were tested to determine the relative utility in terms of operational constraints, resolution, timeliness and cost (Newmark et al., 1992). Based on the relative success of these techniques, a subset was chosen for fielding at the gasoline spill site. In this demonstration, the primary monitoring techniques included temperature measurements, electrical resistance tomography (ERT), induction logging and tiltmeter surveys.

Eleven monitoring boreholes were constructed, forming a subsurface network superimposed over the heating well pattern. Each well was designed for multiple purposes, with $5 \mathrm{~cm}$ diameter non conductive fiberglass casing fitted with four fixed thermocouples and 10 steel ERT electrodes. An additional borehole in the center of the field was completed without electrodes or thermocouples. The steel heating and extraction wells were similarly fitted with fixed thermocouples for additional temperature information in the field.

\section{TEMPERATURE MEASUREMENTS}

Temperature measurements made in the monitoring wells provided the "ground truth" for describing the extent of resistance heating and the 
progress of the steam fronts through the field. Temperature measurements and induction logs obtained in the temperature monitoring wells have proved to be essential for verifying anomalies seen in the tomographic images. Two types of temperature measurements were obtained; borehole temperature logs and fixed thermocouple measurements.

Temperatures were logged daily in all the monitoring boreholes. Due to the high thermal gradients experienced in the field (reaching $80^{\circ} \mathrm{C}$ over a meter or so in depth), standard temperature logging devices were not adequate. Temperature loggers developed at UCB utilizing an optical temperature sensor produced excellent results. Since the sensor measures the radiation from the well casing, it is nearly insensitive to air convection in the boreholes, and the probe affects the borehole temperature less than a standard contact probe would. The system was designed for rapid response; as many as 11 wells can be logged simultaneously in less than an hour. The temperature logs show the details of the heating phenomena through time (Figure 2). During the electrical pre-heat, joule heating of the conductive clay-rich units resulted in higher temperatures in the vadose zone than in the saturated clays. Some of the highest temperatures in the saturated zone were measured in the underlying gravel layer, suggesting that fluid advection was occurring in this permeable zone. Temperature logs obtained during the first steam pass reveal the progress of steam into the more permeable sand and gravel units in detail. In general, the steam penetrates the most permeable units identified in the lithology log. However, in some cases, steam does not readily penetrate apparently permeable units; indicating a large degree of complexity in the flow pathways in this extremely heterogeneous soil (see, for example, the interval between $27-30 \mathrm{~m}$ in Figure 2). By the conclusion of the second steam pass, a combination of conductive and convective heating had resulted in a $25 \mathrm{~m}$ thick zone of soil at or near steam temperature. The only interval at cooler temperatures was the relatively thick clay-rich zone in the vicinity of the water table.

Fixed thermocouples installed in all monitoring and heating wells provided fixed point temperature diagnostics, with measurements recorded around the clock. The time histories of individual thermocouples provide accurate information regarding the heating and cooling at specific locations as a response to electrical heating, steam injection, cool fluid recharge and conductive heating and cooling (Figure 3 ).

\section{ELECTRICAL RESISTANCE TOMOGRAPHY (ERT)}

Electrical Resistance Tomography (ERT) proved to be the most successful technique for providing near real-time imaging of the active thermal and hydrologic processes between wells (Ramirez et al., 1994). ERT images describe the electrical resistivity distribution in the plane between two 
imaging boreholes. Tomographic images of the electrical resistivity distribution between two boreholes are constructed using a dipole-dipole measurement technique to measure the bulk electrical resistivity distribution in the soil mass. Since the electrical properties of the formation are affected by primary lithology, temperature, fluid saturation and fluid chemistry, ERT is useful for tracking both the thermal and hydrologic processes produced during Dynamic Underground Stripping. As a characterization tool, the ERT baseline (absolute) images are useful for delineating the lateral extent and character of individual units identified at the borehole (Figure 4). At this site, the gravel layers are electrically resistive due to their low clay content; the ERT images reveal the actual connections between sand and gravel layers, proving to be excellent predictors of steam movement.

To track changing conditions, ERT difference images were generated between baseline data and data taken during operations. These images only show the changes that have occurred between the two datasets. They proved essential for process control, delineating the progress of the steam through the subsurface, and detecting cold spots not yet fully heated. During steam injection, ERT difference images were generated daily, less often during electrical heating. Eight or nine images could be collected and processed in an average workday, with the results available for review. This timeliness is essential for control of the process, and led to greater confidence in the overall safety and effectiveness of the project. The steam front moving through unheated ground produced the largest change in electrical properties, reducing the resistivity by as much as $60 \%$ of the initial value.

Previous work by Newmark and Wilt (1992) and Ramirez and others (1993) suggests that the resistivity decreases are due primarily to the large temperature increases, and to a lesser extent to changes in fluid saturation or fluid conductance. Waxman and Thomas (1974) showed that the electrical conductivity of exchangeable cations in the sediments may constitute a significant proportion of the total electrical conductance. These ions provide parallel conduction path that is separate from the conduction path through pore space. The saturation-porosity-electrical resistivity relationships are different for this path than for fluid-filled pores. The effects become more significant with increasing clay content, decreasing fluid saturation and increasing fluid resistivity. The observed changes in electrical properties are adequately predicted using a model that accounts for the electrical conductivity from the double layer associated with the clay minerals (e.g., Newmark and Wilt, 1992, Ramirez et al., 1993, Ramirez et al., 1994). Other factors influence the electrical properties of the formation. The injected steam entrains fluid droplets of water from the boiler, which in this case is more resistive than the resident ground water. The displacement of pore water by steam should similarly increase the resistivity. However, the combined effect of increased temperature, changes in saturation and fluid conductance results in a decrease in electrical resistivity in the steamed zones. Ramirez and others 
(1994) apply Chesnut and Cox's (1978) -modification to the Waxman-Smits equation (Waxman and Thomas (1974)):

where

$$
R_{t}=\frac{\left(\phi S_{W}\right)^{-v} R_{W}}{1+R_{W} B Q_{v b}\left(\phi S_{W}\right)^{-1}}
$$

$\mathbf{R}_{\mathbf{W}}=$ water resistivity, ohm-cm

$\mathbf{R}_{\mathbf{t}}=$ resistivity of water-bearing sediment (or rock), ohm-cm

$\phi=$ fractional porosity

$\mathrm{S}_{\mathrm{W}}=$ water saturation, fraction of pore volume

$B=$ equivalent conductance of exchangeable cations, $\left(\mathrm{cm}^{3} / \mathrm{meq}\right) /(\mathrm{ohm}-\mathrm{cm})$

Qvb = cation exchange capacity of sediment, meq per $\mathrm{cm}^{3}$ of bulk volume

$v=$ combined saturation and porosity exponent, typically about 2

Using this relationship, the estimated lower bound for liquid saturations in the lower steam zone is 0.5 (Ramirez et al., 1994).

\section{INDUCTION LOGS}

Induction logs were obtained in all the monitoring wells before, during and after both electrical heating and steam injection (Boyd et al., 1994). Presteam induction logs show close correlation with lithostratigraphy, and are useful for identifying the more permeable gravels. The site is heterogeneous, composed of unconsolidated alluvium, with interbedded clays, sands and gravels. Although the pore fluids are fresh, the large abundance of clay minerals in the formation results in high electrical conductance throughout. Therefore, high-permeability gravels are identified by relatively high resistivity, the tighter clays and silts by low resistivity. The baseline resistivity profiles provide good predictions of which units will take steam (Figure 5).

Electrical resistivity decreases in the steamed zone. The induction logs reveal the changes in formation electrical properties as a response to steam injection in greater vertical detail than is provided by the crosshole ERT images at this site. The induction logs are useful for detailed lithologic characterization and to aid in the calibration and interpretation of the ERT images.

\section{TILTMETER MONITORING}

Tiltmeters were successfully used to monitor the spread of the steam fronts using two analysis techniques (Hunter and Reinke, 1993). Tiltmeters 
are extremely sensitive bubble levels, capable of detecting very small nearsurface angular deformations (to $10^{-9}$ radians) resulting from expansion or contraction of the subsurface due to pressure or thermal effects. Tiltmeter monitoring is particularly attractive for environmental applications, as the instrumentation constitutes a surface array, and is noninvasive.

During the Dynamic Underground Stripping Project demonstration, an array of 17 tiltmeters was used to monitor subsurface steam injection. The sensors were emplaced at about $3 \mathrm{~m}$ depth around the circle of injection wells, at distances ranging from $35-60 \mathrm{~m}$ from the central extraction wells.

Prior to steaming, short term water injection tests were performed for site characterization. The tilt signals from such tests can indicate variations in reservoir properties. The tests revealed preferential flow directions in the lower aquifer (generally to the north and east for the two wells to the north, toward the south and west for the two wells to the south, more homogeneous conditions near the two remaining wells); these predictions were consistent with later evidence of steam flow. Initial analysis indicated that the reservoir that corresponds to the lower steam zone is of limited lateral extent, a result supported by analyses of hydraulic testing of wells in the field.

During steam injection, two types of analyses were used. Long-term data indicates the global growth of the heated zone over a period of several days. As the steam front approaches an individual tiltmeter, the background signal changes; the subsequent rollover of the trend is interpreted as the steam zone approaching and passing under the tiltmeter site (the tilt vector tilts out as the steam front approaches the tiltmeter, and tilts back in as the front passes behind it.) The long-term data were used as a back up system for monitoring the outward growth of the steam zone.

In addition to the long-term data collection, short-term well tests were conducted during which individual injectors were shut in for about one hour. Analyses of the pressure transients associated with these tests indicate the spatial distribution of fluids around the well being tested. Each test was analyzed to determine the distance of the steam front from the injection well in each of six directions (Figure 6). These analyses were commonly repeated, with the sextants rotated $30^{\circ}$ to evaluate the consistency of the results. Results of these analyses are supported by independent observations in the field; in particular, the arrival of steam at the monitoring wells. The tiltmeter analyses extended our understanding of steam movement in the horizontal plane far beyond the limits of the subsurface monitoring network.

\section{SUMMARY}

The monitoring techniques fielded during the Dynamic Underground Stripping Project demonstration played a crucial role in process control as well as characterization. Temperature measurements revealed the details of the heating phenomena at specific locations over time. Electrical Resistance 
Tomography (ERT) indicated the preferred steam pathways and provided near real-time images of both heating fronts and saturation changes. The induction logs were essential for detailed lithologic characterization and to aid in the calibration and interpretation of the ERT images. Tiltmeters defined the relative shape of the steam fronts emanating from individual injectors and the outer perimeter of the steamed zones.

During electrical heatirg, temperature measurements provided the ground truth for bench marking progress. ERT images gave the first indications of the presence of fluid advection caused by temperature gradients in permeable zones. During steam injection, the ERT and tiltmeter results were essential for effective control of the operations. Temperature measurements at fixed points were inadequate for the level of control required. Both ERT images and tiltmeter analyses provided information regarding the location of the steam fronts between individual measuring points. Knowledge of the shape of the steam fronts and the preferential flow paths led to changes in operational strategy in order to limit the growth of the steam zone in less advantageous directions or to sweep previously unheated zones more effectively. These monitoring techniques provide data essential for developing operational strategy, understanding the processes and for rapid decision-making during operations.

\section{ACKNOWLEDGMENTS}

The success of this project is due to the dedication and determination of a large team of contributors. The authors would like to thank all the investigators, students, and support personnel who made the Dynamic Underground Stripping Project a success. Kent Udell and Ron Goldman of UCB developed the optical temperature logging system. In particular, the authors thank John Carbino, Sierra Boyd, Janet Ricca, Mike Wilt, Rick Reinke, Ron Goldman, Kent Kenneally, Dave Kayes and a host of UCB students for data acquisition. Jane Beatty, Dave Vigil and Greg Didion did much of the programming and process design, without which these data might not have been collected. This work was greatly improved through discussions with Abe Ramirez, Roger Aines, Paul Kasameyer, Mike Wilt, and Dwayne Chesnut. This work was funded by the Office of Technology Development of the United States Department of Energy, EM-55. Work performed under the auspices of the U. S. Department of Energy by the Lawrence Livermore National Laboratory under contract W-7405-ENG-48.

\section{REFERENCES}

Boyd, S., R.L. Newmark and M. Wilt, 1994, Induction logging for the Dynamic Underground Stripping Project, Dynamic Underground Stripping Gasoline Spill Site Report, Lawrence Livermore National Laboratory, Livermore, Calif. (in press). 
Chesnut, D.A. and D.O. Cox, 1978, "Log Analysis in a Rocky Mountain Heavy Oil Reservoir," SPWLA Nineteenth Annual Logging Symposium, June 13-16.

Dresen, M.D., F. Hoffman and S. Lovejoy, 1986, Subsurface distribution of hydrocarbons in the Building 403 area at LLNL, Lawrence Livermore National Laboratory, Livermore, Calif., (UCID-20787).

Huner, R. J., and R. F. Reinke, 1993, Tiltmeter mapping of steam zones during steam injection, February - June, 1993, Final Report, Lawrence Livermore National Laboratory Contract LLNL-B200606.

Newmark, R.L., ed., 1992, Dynamic Underground Stripping Project Clean Site Interim Engineering Report, Lawrence Livermore National Laboratory, Livermore, Calif., LLNL UCRL-ID-110064.

Newmark, R. and M. Wilt, 1992, Changes in formation electrical properties during steam flood, 62nd Ann. Internt. Mtg., Soc. Expl. Geophys., Expanded Abstracts, 488-491.

Ramirez, A., W. Daily, D. LaBrecque, E. Owen and D. Chesnut, 1993, Monitoring an underground steam injection process using electrical resistance tomography, Water Resources Research, o. 29, No. 1, 73-87.

Ramirez, A, J. Beatty, J. Carbino, W. Daily and R. Newmark, 1994, Monitoring Thermal Treatment Processes Using Electrical Resistance Tomography, Dynamic Underground Stripping Gasoline Spill Site Report, Lawrence Livermore National Laboratory, Livermore, Calif. (in press).

Udell, K. S., and J. R. Hunt, 1987, Analysis of rates of gasoline dissolution by groundwater pumping - cylindrical geometry, Final Report, Lawrence Livermore National Laboratory Contract LLNL-9850705.

Waxman, M.H. and E.C. Thomas, 1974, "Electrical Conductivities in Shaly Sands - I. The Relation Between Hydrocarbon Saturation and Resistivity Index; II. The Temperature Coefficient of Electrical Conductivity," Journal of Petroleum Technology, (Feb.) 213-225; Transactions AIME, 257.

\section{FIGURE CAPTIONS}

Figure 1. The Dynamic Underground Stripping process. Steam drives contaminated ground water toward extraction wells and then heats the soil to distill organics. Electrical heating dries and distills impermeable clays. Geophysical techniques monitor the process.

Figure 2. Temperature logs reveal the details of heating in well TEP-007:

- electrical heating of the clay-rich units during the pre-heat $(1 / 11 / 93)$,

- steam passing through the most permeable units during the first steam pass $(3 / 11 / 93)$, and

- conductive heating of and later penetration of steam into less permeable units during the second steam pass $(6 / 28 / 93)$. 
Figure 3. Individual thermocouples reveal the thermal history at fixed locations in the field. Shown here is a temperature record from a thermocouple positioned in the gravel unit of the lower steam zone in well TEP-002, located midway between two steam injection wells, each $18 \mathrm{~m}$ away. Each time steam is injected into che lower steam zone, temperatures at this location begin to rise within $24 \mathrm{hr}$, evidence of the extremely high permeability in this zone. During ground water pumping, cool fluids are drawn across this location from outside the steamed area, causing temperatures to decrease. Between the two steam passes, initial recharge of ground water results in rapid cooling; this gives rise to more steady-state conditions.

Figure 4:

Top: ERT absolute images reveal the continuity of lithologic units across image planes. The resistive units correspond to the more permeable sand and gravel zones; the conductive units correspond to the clay-rich intervals. (The apparent pinching-out of units in the center of the image is due to the increase in resolution radius toward the center of each image).

Bottom: ERT images showing the difference between baseline data and subsequent datasets show the progress of the steam fronts across the image plane, starting from the first day of steam injection. This image plane is located approximately $6 \mathrm{~m}$ from the nearest injection well, and is oriented nearly perpendicular to a line linking it and the extraction wells. Small decreases in electrical resistivity are observed within hours of the start of steam injection. Although steam was initially injected into only the lower steam zone (centered at about $35 \mathrm{~m}$ depth), steam leaked into the upper steam zone (centered at about $25 \mathrm{~m}$ depth) through the well completion in the nearby injection well; this is evidenced by the resistivity decreases in both zones in these images. By the end of the first steam pass (Day 36), both the upper and lower steam zones were at or near sieam temperature, with conductive heating occurring in the neighboring clay-rich units. The preferential steam paths closely follow the more resistive units seen in the absolute images.

Figure 5: Induction logs in well TEP-005. In the baseline $\log (11 / 4 / 92$, solid curve), the permeable zones have high resistivity. During the first steam pass $(2 / 24 / 93$, dashed), the narrow heated zone at about $35 \mathrm{~m}$ displays lowered resistivity. After the second steam pass $(7 / 19 / 93$, dotted), a broad zone from about 15-40 $\mathrm{m}$ exhibits both elevated temperatures and diminished resistivity. The narrow aquifer at $35 \mathrm{~m}$ has experienced ground water recharge; hence, its resistivity is indicative of heated saturated conditions compared to the hot, aryer conditions existing during the first steam pass. 
Figure 6: Results of nightly shut-in tests show the growing shape of the steam fronts emanating from two injection wells. Analyses of tests performed the first night after start of steam injection (heavy shading) indicate preferential flow in the north-south direction. The following night's analyses (lighter shading) shows the steam front nearing the extraction wells; steam break-through to the extraction wells occurred during the next day. 


\section{Dynamic Underground Stripping - Section Through Injection Circle}

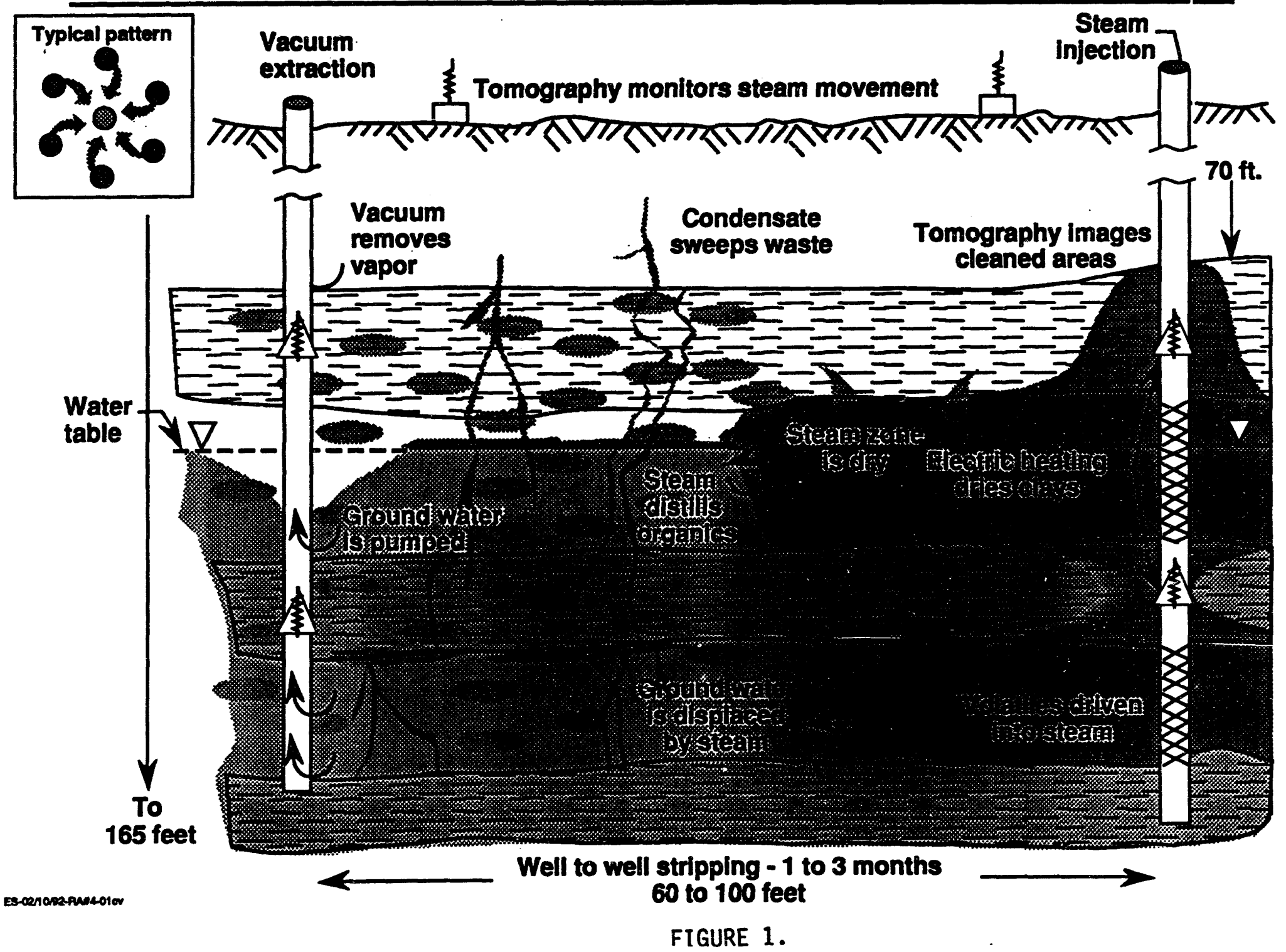


Temperature Logs Inside Injection Ring

Well TEP- 007

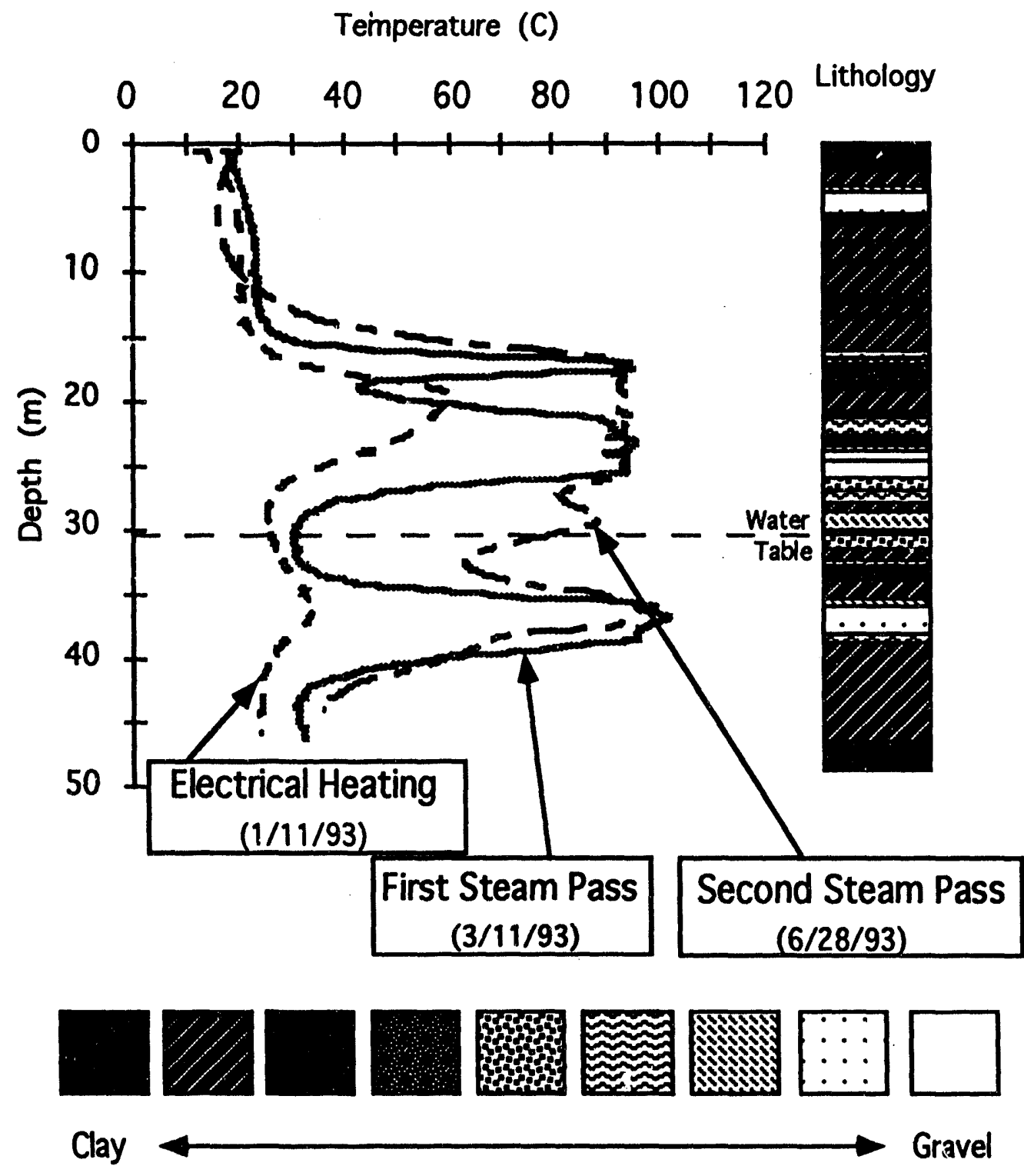

FIGURE 2. 
Fixed Thermocouple Response

Well TEP-002, Depth $40 \mathrm{~m}$

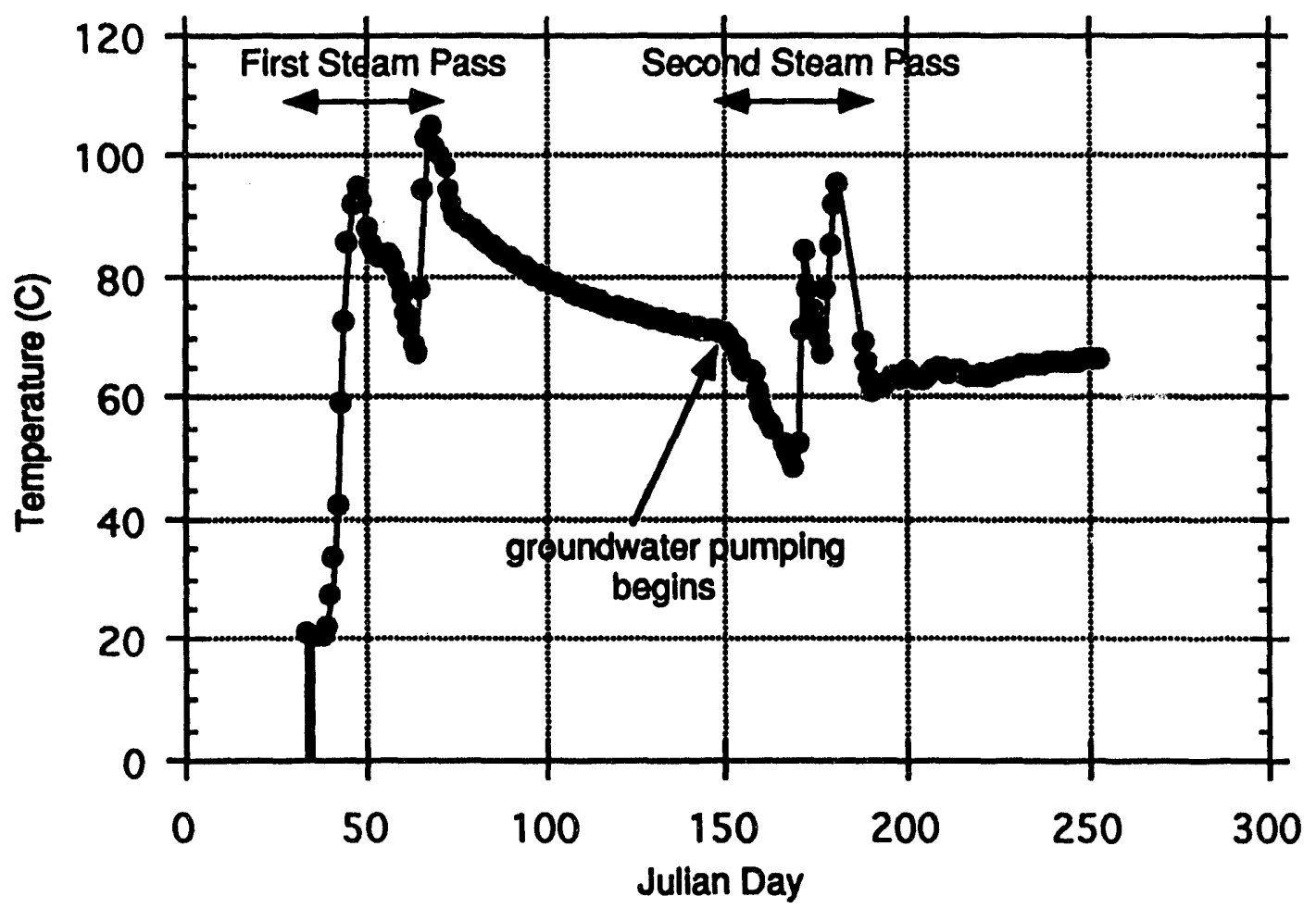

FIGURE 3. 


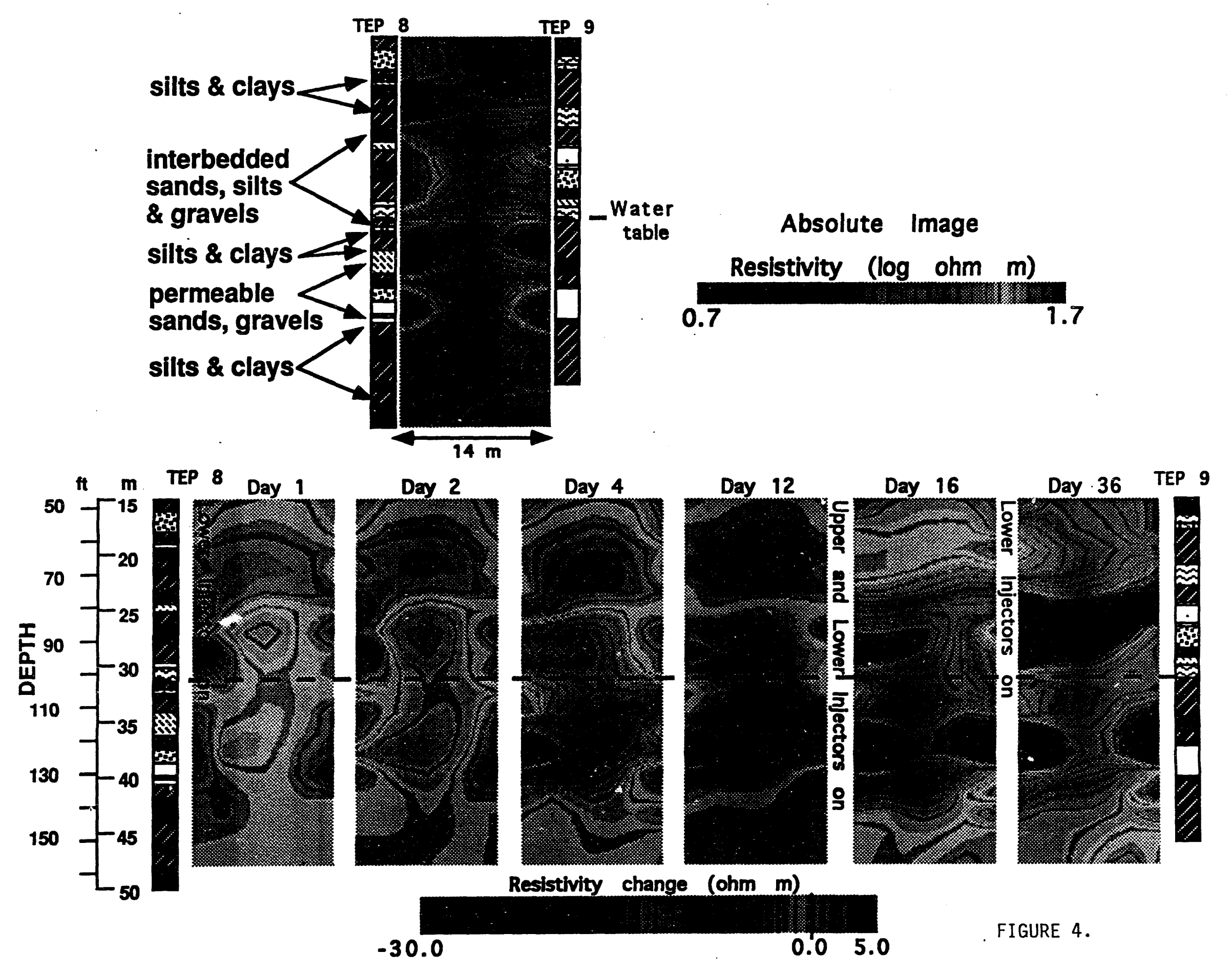



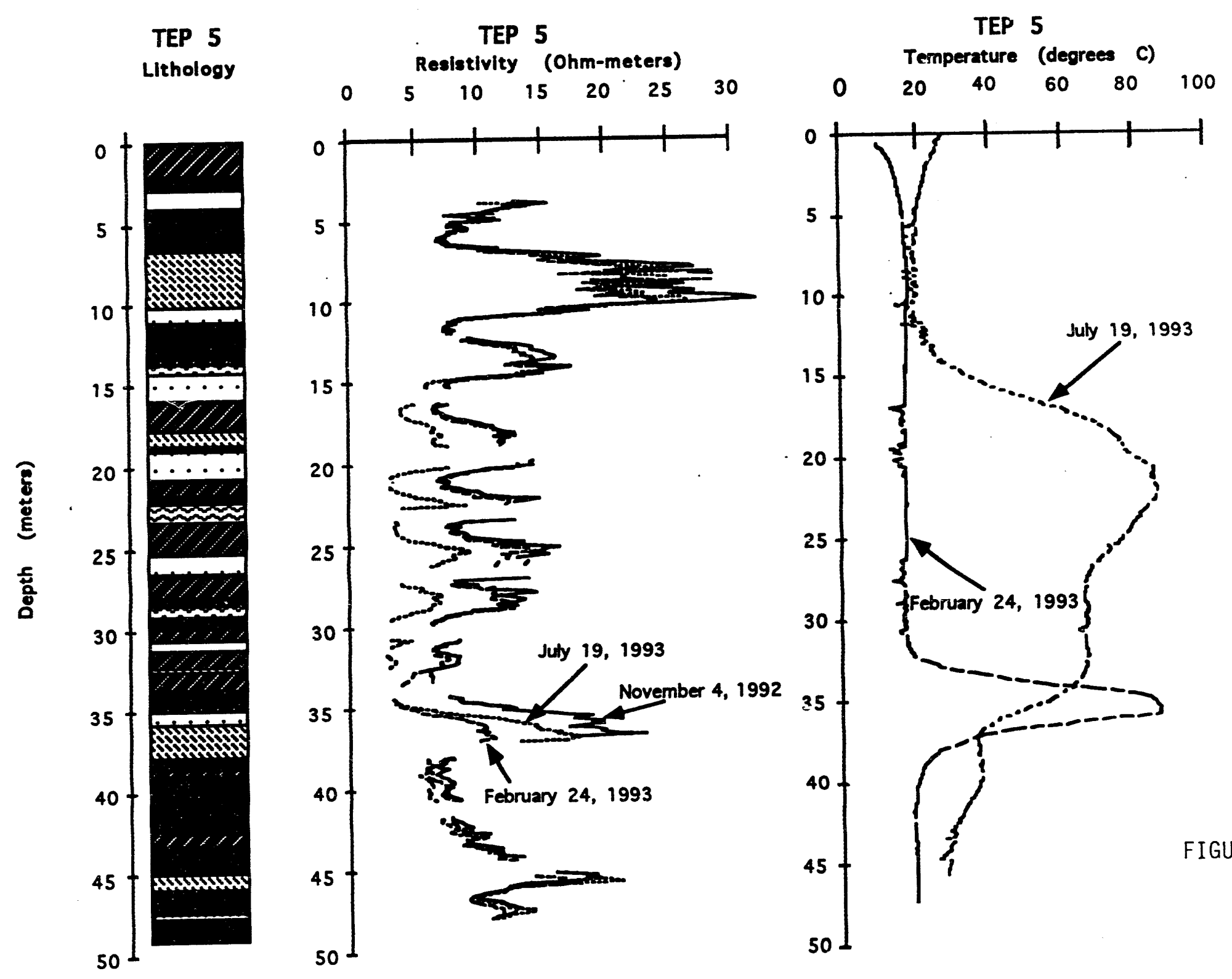

FIGURE 5. 


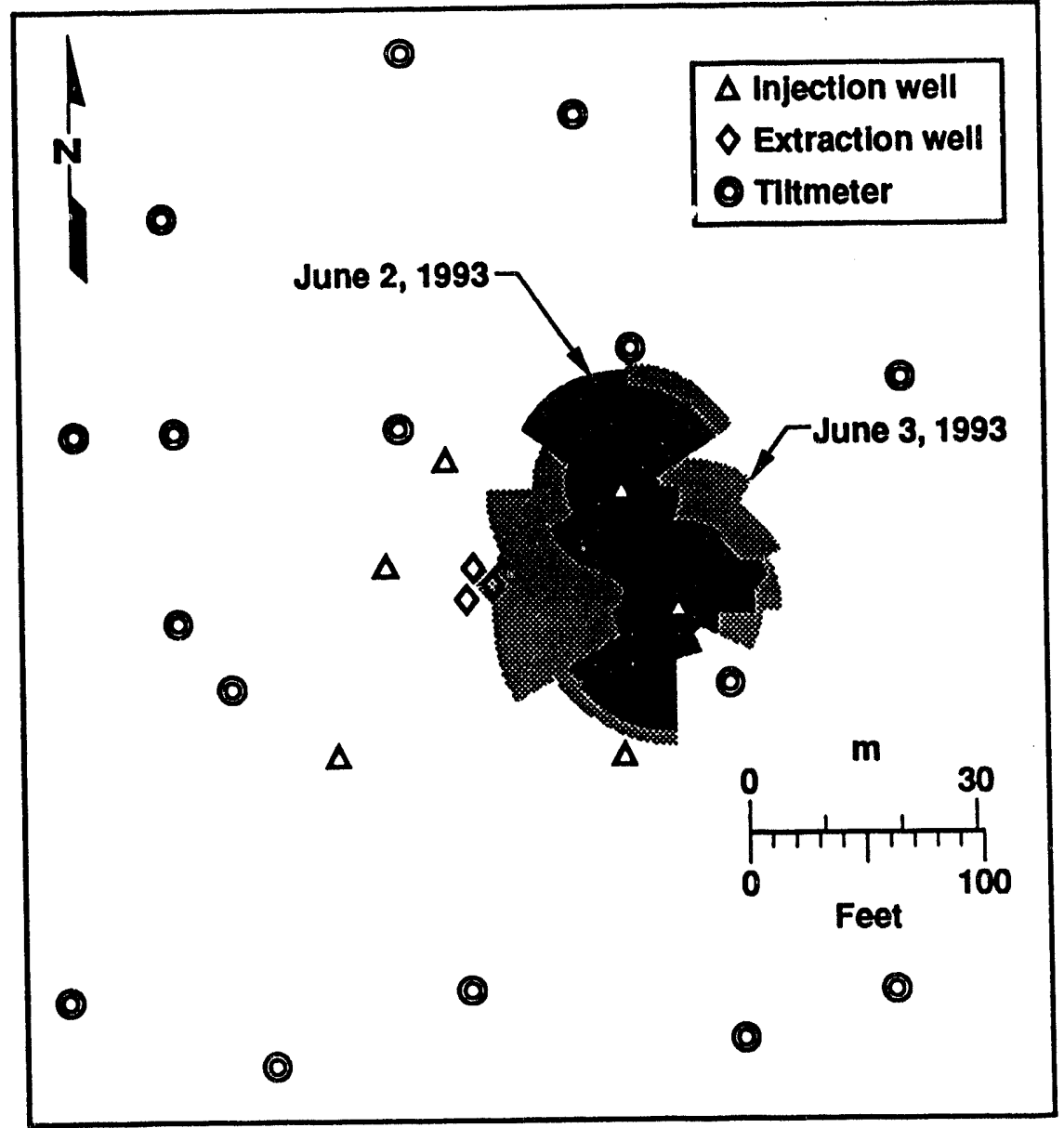

FIGURE 6. 

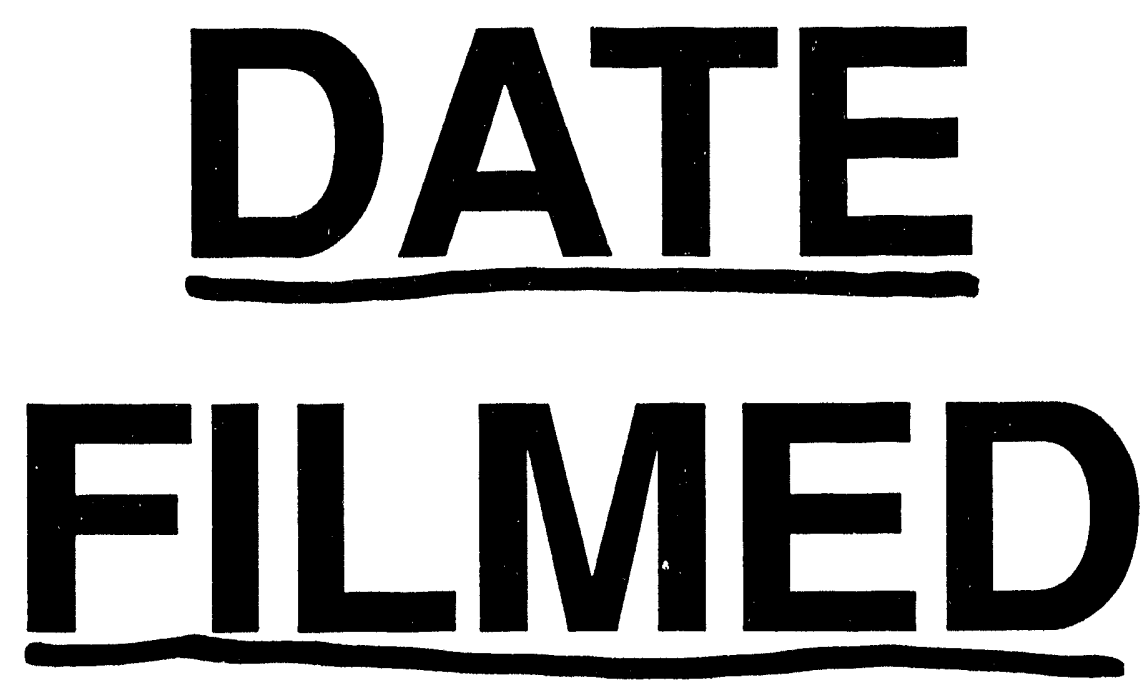

$6 / / 5 / 94$
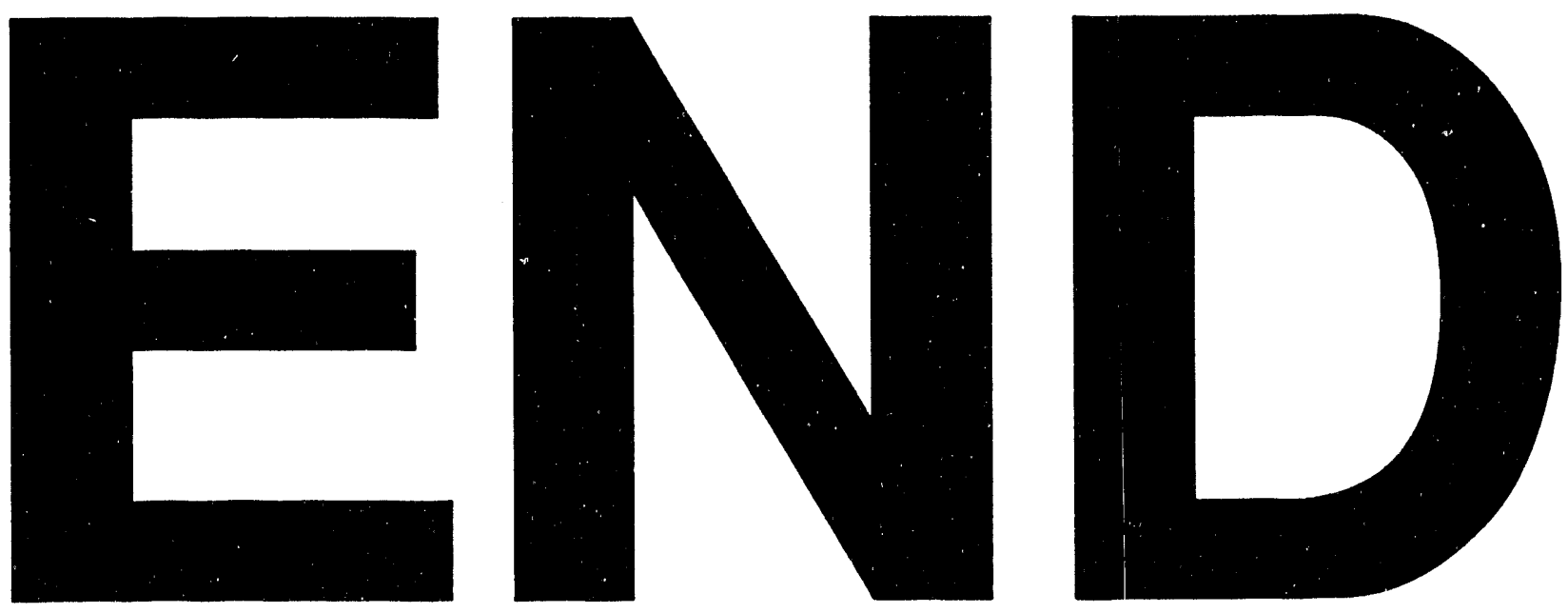


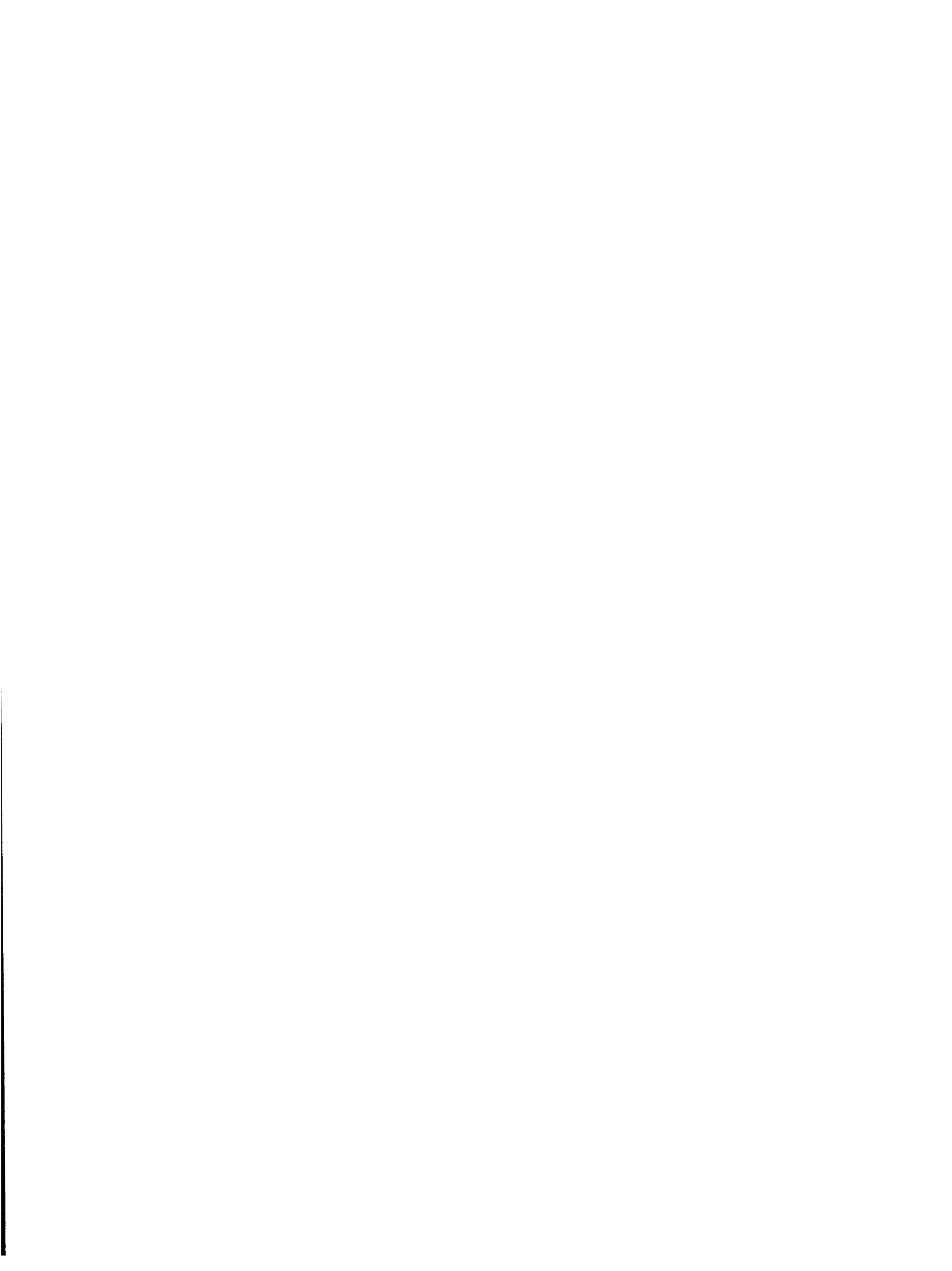

